\title{
Korelasi Persepsi terhadap Kebutuhan Fisioterapi Antenatal untuk Mengatasi Masalah Muskuloskeletal Ibu Hamil
}

\author{
${ }^{1}$ Roikhatul Jannah, ${ }^{1}$ Dwi Agustina, ${ }^{2}$ Windya Puspa Faradisa \\ ${ }^{1}$ Poltekkes Kemenkes Jakarta III \\ ${ }^{2}$ Optimal Physiotherapy Rehab Center \\ email: ro_ikha@yahoo.com
}

Received: 27-04-2019, Review: 18-06-2019, 03-07-2019, Accepted: 18-07-2019

\begin{abstract}
ABSTRAK
Fisioterapi merupakan bentuk pelayanan kesehatan yang penting bagi ibu hamil. Penelitian ini bertujuan untuk mengetahui korelasi persepsi ibu hamil terhadap kebutuhan layanan fisioterapi antenatal dalam mengatasi gangguan muskuloskeletal. Desain penelitian cross sectional dilaksanakan di Puskesmas Kecamatan Cipayung dengan sampel 103 responden yaitu para ibu hamil. Metode pengumpulan data dilakukan lewat penyebaran kuesioner. Analisa data yang dilakukan meliputi analisa univariat dan bivariat menggunakan Uji Chisquare. Hasil penelitian responden berpendidikan SMA/sederajat sebanyak $61,2 \%$, penghasilan keluarga menengah $(37,9 \%)$, tidak bekerja sebanyak $82,5 \%$, dengan pengetahuan fisioterapi kurang $(70,9 \%)$, nyeri pinggang bawah $(63,1 \%)$, dan persepsi merasa tidak butuh fisioterapi antenatal 52,4\%. Faktor yang secara signifikan berpengaruh terhadap persepsi ialah faktor tingkat pendidikan, sebesar $\mathrm{p}=0,041$. Faktor pekerjaan tidak memiliki pengaruh terhadap persepsi ibu hamil $\quad(p=0,000)$. Penelitian ini merekomendasikan untuk ditingkatkannya promosi tentang layanan antenatal fisioterapi agar lebih berperan aktif dalam meningkatkan kesehatan wanita.
\end{abstract}

Kata Kunci: persepsi, gangguan musculoskeletal, fisioterapi antenatal

\section{ABSTRACT \\ Physiotherapy is a form of health care that is important for pregnant women. This study discusses the factors that shape the perception of pregnant women on the needs of antenatal physiotherapy services in dealing with musculoskeletal disorders. This cross-sectional design study was conducted}

in the Cipayung Sub-district Health Center with a sample of 103 respondents, namely pregnant women, through the questionnaire data collection method. Data analysis was performed using univariate and bivariate analysis using the Chi-square Test. Research results Respondents with high school education / equivalent amounted to $61.2 \%$, the highest level of family freedom was IDR 2,500,000-3,500,000 (37.9\%), respondents did not work as much as $82.5 \%$, with "lacking" knowledge about physiotherapy (70, 9\%), musculoskeletal disorders of lower back pain (63.1\%), and perceptions not requiring antenatal physiotherapy as much as $52.4 \%$. The test result ( $p$ value) is the most significant of the education level factors, amounting to $p=0.041$, and has absolutely no significance with employment factors ( $p=$ 0.000). Data analysis of this study proves the fact that the research does not deny to test the perceptions of pregnant women. This study discusses the promotion of antenatal physiotherapy services to be more active in improving women's health.

Keywords: perception, needs, antenatal physiotherapy

\section{PENDAHULUAN}

Kehamilan adalah suatu keadaan fisiologis yang menghasilkan perubahan fisiologis sehingga menimbulkan ketidaknyamanan (Manurung, 2011). Perubahan fisiologis yang terjadi pada masa kehamilan berhubungan langsung pada metabolisme fetus. Perubahan fisiologis merupakan kulminasi interaksi biochemical yang terjadi antara tiga sistem interaksi yaitu maternal, fetal dan placental (Beckmann, 2010). Perubahan-perubahan fisiologis yang 
terjadi pada masa kehamilan salah satunya adalah perubahan fisiologis pada sistem muskuloskeletal, sebagai dampak dari hormon dan anatomi, di mana dalam konteks ini faktor biomekanik turut memiliki pengaruh dalam menimbulkan ketidaknyamanan, yaitu perubahan berat badan sehingga merubah postur dan nyeri pada sistem musculoskeletal Yasobant, 2014). Nyeri pinggang akut memiliki prevalensi terbesar yaitu $55.6 \%$ dan nyeri pinggang kronis $35.4 \%$, diikuti nyeri pergelangan kaki sebesar $24.9 \%$ dan nyeri lutut $16.6 \%$ (Liddle, 2015). Cochrane Systematic Review mengatakan bahwa sebesar dua per tiga ibu hamil memiliki nyeri pinggang (60\%) dan nyeri pelvic (20\%). Howell (2012) berpendapat, sebesar 31.7\% ibu hamil memiliki disfungsi simpisis pubis (Howell, 2012)

Ibu hamil mengatasi nyeri pada musculoskeletal dengan mengonsumsi obatobatan dan datang ke layanan fisioterapi serta layanan alternatif pelayanan medis lainnya (Sinclair, 2014). Fisioterapi memegang peranan yang penting pada masa antenatal maupun postnatal karena memberikan keuntungan jangka panjang bagi wanita. Hal ini bermanfaat untuk mengatasi gangguan muskuloskeletal selama kehamilan, menjaga kebugaran dan ketahanan kardiovaskular, menjaga berat badan dan menjaga kondisi psikologis melalui antenatal exercise (Nayak, 2015) Hal ini karena penggunaan layanan fisioterapi dapat meningkatkan kemampuan fungsional pada ibu hamil dengan keluhan musculoskeletal (Richards, 2012)

Pada dasarnya ibu hamil membutuhkan fisioterapi. Hal itu tidak serta merta secara otomatis menjadi suatu kebutuhan,kecuali muncul perasaan tidak nyaman atau kadar sakit tertentu. Faktor perasaan tersebut akan menimbulkan persepsi (Jalaludin, 2007). Persepsi merupakan pengalaman tentang objek, peristiwa atau hubungan yang diperoleh dengan menyimpulkan informasi dan kemudian ditafsirkan (Jalaludin, 2007 ; Suharman, 2005). Persepsi setiap orang berbeda-beda, tergantung dari beberapa faktor yang mempengaruhi individu yang melakukan persepsi. Ada beberapa faktor yang mempengaruhi persepsi yaitu karakteristik individu, pengalaman, pengetahuan, motivasi, sikap serta usia, sosial ekonomi, tingkat pendidikan, kepribadian dan pekerjaan (Haposanita, 2014). Salah satu aspek yang berperan dalam mempersepsi sesuatu adalah pengetahuan, pengalaman yang dimiliki (Juwita, 2004). Kondisi ini adalah sebuah indikasi bahwa setiap ibu hamil membutuhkan pengetahuan yang memadai terkait dengan fisioterapi agar kebutuhan terkait fisiopterapi dapat dianalisis dengan sesuai.

Ibu hamil dengan atau tanpa keluhan muskuloskeletal biasanya datang ke Pelayanan Antenatal. Namun, di Indonesia kecenderungan tersebut masih sangat kecil. Ibu yang mengunjungi dan memanfaatkan pelayanan fisioterapi merupakan suatu fenomena yang unik sehingga perlu dilakukan penelitian terhadap factor-faktor yang memengaruhi persepsi ibu hamil dalam mengunjungi fisioterapi. Penelitian ini bertujuan untuk menemukan ada tidaknya korelasi dari faktor tingkat pendidikan, faktor penghasilan, faktor pengetahuan, dan faktor pekerjaan terhadap perspesi ibu hamil mengenai kebutuhan layanan fisioterapi.

\section{METODE}

Penelitian ini deskriptif analitik observasional dengan desain cross sectional. Penelitian dilaksanakan di Puskesmas Kecamatan Cipayung selama bulan April hingga Juni 2018. Populasi penelitian merupakan seluruh ibu hamil di Puskesmas Kecamatan Cipayung. Sampel penelitian diambil dengan teknik random sampling, yaitu sebanyak 103 hamil dengan gangguan muskuloskeletal. Variabel bebas adalah 
faktor yang mempengaruhi persepsi, sedangkan variabel terikat adalah nyeri muskuloskeletal.

Pengumpulan data dilakukan dengan teknik wawancara menggunakan kuesioner. Kuisioner berisi data mengenai tingkat pendidikan, pekerjaan, penghasilan, pengetahuan mengenai muskuloskeletal. Variabel persepsi diukur dengan menggunakan kuisioner dengan skala Likert dengan empat pilihan jawaban (sangat setuju, setuju, tidak setuju, sangat tidak setuju).

\section{HASIL PENELITIAN}

Identifikasi gambaran karakteristikresponden, disfungsi muskuloskletal pada ibu periode antenatal dipaparkan dalam Tabel:

Tabel 1.

Distribusi Karateristik responden (n=103)

\begin{tabular}{|c|c|c|}
\hline Kategori & Frekuensi & $\%$ \\
\hline \multicolumn{3}{|l|}{ Tingkat Pendidikan } \\
\hline SD & 6 & 5,8 \\
\hline SMP/Sederajat & 15 & 14,6 \\
\hline SMA/Sederajat & 63 & 61,2 \\
\hline Diploma & 7 & 6,8 \\
\hline Sarjana & 10 & 9,7 \\
\hline Magister & $\begin{array}{c}2 \\
103\end{array}$ & $\begin{array}{c}1,9 \\
\mathbf{1 0 0}\end{array}$ \\
\hline \multicolumn{3}{|l|}{ Pekerjaan } \\
\hline Bekerja & 18 & 17,5 \\
\hline $\begin{array}{c}\text { Tidak bekerja } \\
\text { Total }\end{array}$ & $\begin{array}{c}85 \\
103 \\
\end{array}$ & $\begin{array}{l}82,5 \\
\mathbf{1 0 0}\end{array}$ \\
\hline \multicolumn{3}{|l|}{ Penghasilan Keluarga } \\
\hline$<\mathrm{Rp} 1.500 .000($ bawah $)$ & 10 & 9,7 \\
\hline Rp1.500.000-2.500.000 (menengah) & 21 & 20,4 \\
\hline Rp2.500.000-3.500.000 (menengah atas) & 39 & 37,9 \\
\hline$>\mathrm{Rp} 3.500 .000($ atas $)$ & $\begin{array}{c}33 \\
103 \\
\end{array}$ & $\begin{array}{c}32 \\
100 \\
\end{array}$ \\
\hline \multicolumn{3}{|l|}{ Tingkat Pengetahuan } \\
\hline Baik & 7 & 6,8 \\
\hline Cukup & 23 & 22,3 \\
\hline Kurang & $\begin{array}{c}73 \\
\mathbf{1 0 3} \\
\end{array}$ & $\begin{array}{l}70,9 \\
\mathbf{1 0 0} \\
\end{array}$ \\
\hline \multicolumn{3}{|l|}{ Persepsi Kebutuhan } \\
\hline Butuh & 49 & 47,6 \\
\hline Tidak Butuh & $\begin{array}{c}54 \\
103\end{array}$ & $\begin{array}{l}52,4 \\
100 \\
\end{array}$ \\
\hline
\end{tabular}

Ibu hamil memiliki pendidikan akhir SMA/sederajat $(61,2 \%)$ dan minoritas memiliki pendidikan akhir magister $(1,9 \%)$, tidak bekerja $(82,5 \%)$, tingkat penghasilan keluarga menengah atas (Rp2.500.000Rp3.500.000) (37,9\%). Responden dengan pengetahuan yang kurang mengenai layanan fisioterapi $(70,9 \%)$ dan responden yang 
kehamilan $(52,4 \%)$.

Tabel 2. Distribusi Kejadian Disfungsi Muskuloskeletal Periode ntenatal (n=103)

\begin{tabular}{lccc}
\hline Disfungsi & Trimester pertama & Trimester kedua & Trimester ketiga \\
$n=4$ & $n=32$ & $n=67$ \\
\hline Low Back Pain & 50 & 65,6 & 62,7 \\
Disfungsi Pelvic Girdle & 50 & 43,8 & 49,3 \\
Disfungsi Simpisis Pubis & 25 & 25 & 22,4 \\
Kram & 50 & 56,3 & 62,7 \\
Sindroma Carpal Tunnel & 25 & 6,3 & 6,0 \\
Thoracic and Rib Cage & 50 & 34,4 & 17,9 \\
Dysfunction & 0 & 31,3 & 29,9 \\
Inkontinensia Urin & & & \\
\hline
\end{tabular}

Disfungsi musculoskeletal yang sering dirasakan ibu sejak hamil trimester pertama sampai dengan trimester ketiga adalah low back pain (63\%) dan kram $(60,2 \%)$.
Sindroma carpal tunnel adalah gangguan yang paling jarang dirasakan oleh ibu hamil $(6,8 \%)$.

Tabel 3. Faktor yang Mempengaruhi Persepsi Pemanfaatan layanan Fisioterapi Periode Antenatal $(n=103)$

\begin{tabular}{cllll}
\hline \multicolumn{1}{c}{ Variabel } & \multicolumn{1}{c}{ Kategori } & \multicolumn{1}{c}{ Butuh } & \multicolumn{1}{c}{ Tidak Butuh } & p value \\
\hline \multirow{5}{*}{ Tingkat Pendidikan } & SD & $1(16.7 \%)$ & $5(83.3 \%)$ & \\
& SMP/Sederajat & $7(46.7 \%)$ & $8(53.3 \%)$ & \\
& SMA/Sederajat & $26(41.3 \%)$ & $37(58.7 \%)$ & \multirow{2}{*}{0.042} \\
& Diploma & $6(85.7 \% 0$ & $1(14.3 \%)$ & \\
& Sarjana & $7(70 \% 0$ & $3(30 \%)$ & \\
& Magister & $2(100 \%)$ & $0(0.0 \%)$ & \\
\hline \multirow{2}{*}{ Pekerjaan } & Bekerja & $11(61.1 \%)$ & $7(38.9 \%)$ & \multirow{2}{*}{0.314} \\
& Tidak bekerja & $38(44.7 \%)$ & $47(55.3 \%)$ & \\
\hline \multirow{5}{*}{ Penghasilan Keluarga } & Rp1.500.000 & $3(30 \%)$ & $7(70 \%)$ & \\
& Rp2.500.000-3.500.000 & $6(28.6 \%)$ & $15(71.4 \%)$ & 0.001 \\
& $>$ Rp3.500.000 & $25(78.5 \%)$ & $24(61.5 \%)$ & \\
\hline Tingkat Pengetahuan & Baik & $7(100 \%)$ & $0(0 \%)$ & 0.001 \\
\hline & Cukup & $18(78.3 \%)$ & $5(21.7 \%)$ & \\
& Kurang & $24(32.9 \%)$ & $49(67.1 \%)$ & \\
\hline
\end{tabular}

Faktor yang mempengaruhi persepsi ibu hamil daam pemanfaatan layanan fisioterapi masalah disfungsi muskulokeletal adalah faktor tingkat pendidikan $(\mathrm{p}=0,042)$, faktor penghasilan keluarga $(\mathrm{p}=0,001)$, dan faktor tingkat pengetahuan $(\mathrm{p}=0,001)$. Sedangkan faktor pekerjaan tidak mempengaruhi persepsi ibu hamil $(\mathrm{p}=0,314)$.

\section{PEMBAHASAN}

Peneitian ini menyatakan bahwa faktor yang berkorelasi terhadap pembentukan persepsi dalam pemanfaatan layanan fisioterapi adalah faktor pendidikan, 
faktor penghasilan, dan faktor pengetahuan. Tingkat pendidikan mempengaruhi pola pikir, sudut pandang serta penerimaan responden terhadap informasi yang diterimanya, sehingga secara langsung maupun tidak langsung akan mempengaruhi pola pikir, sudut pandang serta penerimaan responden terhadap informasi yang diterimanya (Listiani, 2017) Semakin tinggi tingkat pendidikan, semakin banyak pula pengetahuan yang dimiliki, sehingga individu tersebut akan lebih mudah meneriman serta memahami objek yang akan dipersepsikan (Yustiani, 2013) Teori dari Jacobalis menyatakan bahwa tingkat pendidikan dapat mempengaruhi seseorang dalam berfikir, apakah individu tersebut berfikir rasional atau irasional. Individu dengan tingkat pendidikan rendah memiliki kecenderungan inkonsistensi persepsi yang sangat tinggi. Selain faktor tingkat penghasilan, pada penelitian ini faktor tingkat pengetahuan responden juga berhubungan dengan persepsi kebutuhan layanan fisioterapi antenatal. Salah satu faktor yang mempengaruhi persepsi seseorang adalah pengetahuan, dan pengetahuan ada ketika seseorang telah melakukan penginderaan pada suatu objek dan persepsinya (Bimo, 2010 ; Wardana, 2016)

Semakin tinggi pengetahuan seseorang, maka akan semakin positif persepsinya. Sesuai dengan pendapat Notoadmodjo dalam penelitiannya (Wardana, 2016) yaitu setelah responden melakukan penginderaan maka kemudian akan membentuk keyakinan dan persepsi yang positif, sehingga dapat bersikap dan berperilaku sesuai dengan keyakinan tersebut. Seseorang yang memiliki tingkat pengetahuan yang baik akan merasa membutuhkan akses kesehatan yang lebih banyak untuk upaya perawatan terhadap gejala yang dirasakannya (Wibowo, 2017). Hal ini sejalan dengan hasil penelitian terdahulu yang menyatakan bahwa pengetahuan membantu mengenali berbegai stimulus yang muncul dan kemudian menjadi persepsi (Trisnaniyanti et al, 2010). Pada penelitian lain disebutkan juga bahwa walaupun masyarakat memiliki asuransi atau kartu jaminan kesehatan, mereka lebih memilih mengabaikan keluhan kesehatan dikarenakan kurangnya pengetahuan masyarakat mengenai kegunaan pelayanan kesehatan tersebut (Littik, 2008). Hal tersebut terjadi karena kurangnya sosialisasi pelayanan kesehatan ke masyarakat agar masyarakat mengetahui tujuan dan manfaat pelayanan kesehatan tersebut.

Penelitian ini juga sesuai dengan teori yang menyatakan bahwa persepsi tentang sesuatu yang positif dapat mendorong seseorang untuk melakukan tindakan tersebut (Bimo, 2010). Responden pada penelitian ini dilihat dari gangguan muskuloskeletal yang diderita seharusnya membutuhkan fisioterapi, namun responden kurang memiliki pengetahuan mengenai layanan fisioterapi sehingga memiliki persepsi bahwa responden tidak membutuhkan layanan fisioterapi antenatal. Mereka berfikir bahwa ketidaknyamanan yang mereka alami merupakan suatu hal normal yang nantinya akan sembuh dengan sendirinya, sehingga diabaikan (Manarung, 2011). Pada penelitian ini, ditemukan prevalensi nyeri pinggang pada trimester 1 dan dua lebih rendah dibandingkan trimester ketiga. Nyeri pinggang selama kehamilan diperparah dengan adanya pelunakan ligament dan sendi lumbosacrum karena adanya peningkatan level hormone progesterone dan relaxin. Nyeri pada region pinggang dan pelvic merupakan masalah umum yang terjadi pada masa kehamilan, dengan estimasi $4 \%$ hingga 76\% (O.Ayamniyi et al , 2017). Selama kehamilan, nyeri pinggang bisa menjadi hasil dari sekumpulan interaksi yang kompleks antara perubahan fisik, anatomi serta fisiologis yang muncul selama periode prenatal, dan dapat menyebabkan gangguan aktivitas yang signifikan di seluruh area pinggang (Kanakaris, 2011)). Selain nyeri 
pinggang, sindrom pelvic girdle juga paling tinggi pada trimester ketiga pada penelitian ini. Faktor biomekanikal sangat dapat menambah tekanan pada spine dikarenakan adanya penambahan beban pada perut, penurunan stabilitas pada pelvic, laxity pada sendi Sacrum Iliaka (SI) dan peningkatan mobilitas pada sendi selama kehamilan (Ramachandra et al, 2014). Selanjutnya, kram otot merupakan disfungsi musculoskeletal yang umum terjadi pada wanita hamil dan pada penelitian ini, prevalensi tertinggi ada pada trimester ketiga $(62.7 \%)$. Kram merupakan kontraksi otot yang sangat menyakitkan dan biasanya terjadi pada otot-otot calf yang terjadi pada malam hari (Jacobalis, 2000)

Hasil penelitian ini menunjukkan bahwa tidak adanya hubungan antara pekerjaan dengan persepsi kebutuhan layanan fisioterapi antenatal. Berdasarkan hasil penelitian terdahulu, salah satu faktor yang dapat mempengaruhi persepsi ialah pekerjaan (Abs, 2012). Namun, penelitian ini tidak membuktikan adanya korelasi di antara kedua hal tersebut. dalam penelitian ini tidak terdapat hubungan antar keduanya. Pekerjaan merupakan kegiatan-kegiatan yang dapat menghasilkan uang. Aspek lain yang perlu diingat adalah ada beberapa jenis pekerjaan yang tidak menghasilkan banyak uang, atau dikenal dengan non-profit oriented. Hal ini dapat menjadi indikasi tidak adanya hubungan antar kedua variabel. Tingkat ekonomi merupakan hal yang sangat dibutuhkan untuk memenuhi kebutuhan. Jika tingkat ekonomi responden rendah, maka mereka mengesampingkan kebutuhan yang lebih tinggi demi memenuhi kebutuhan pokok atau kebutuhan sehari-hari. Opini lainnya adalah responden tidak memiliki pengetahuan serta koneksi yang luas untuk mengetahui pelayanan kesehatan yang dibutuhkannya

Hasil penelitian terdahulu menjelaskan bahwa seseorang yang tidak bekerja mempunyai 1.5 kali peluang untuk membutuhkan pelayanan kesehatan dikarenakan lebih memiliki banyak waktu(Field, 2001). Sedangkan penelitian ini menyatakan bahwa seseorang yang tidak bekerja ternyata tidak memiliki urgensitas terhadap pelayanan kesehatan. Literatur lain juga menyebutkan bahwa seseorang yang tidak bekerja lebih sering mengalami gangguan kesehatan psikis atau depresi serta kurangnya pengetahuan mengenai pelayanan kesehatan mana yang dibutuhkannya (Yesil, 2015).

Hasil perhitungan hubungan antara tingkat penghasilan dengan persepsi ibu hamil terhadap kebutuhan layanan fisioterapi antenatal sebagaimana yg dijelaskan pada tabel 2 setelah menunjukkan bahwa ada hubungan yang signifikan antara tingkat penghasilan dengan persepsi ibu hamil terhadap kebutuhan layanan fisioterapi antenatal. Berdasarkan uji tersebut dapat dijelaskan bahwa semakin tinggi pendapatan, maka persepsi seseorang terhadap kebutuhan layanan fisioterapi antenatal juga semakin tinggi.

Hasil ini sesuai dengan teori terdahulu yang mengemukakan bahwa penghasilan seseorang merupakan salah satu faktor yang dapat memengaruhi persepsi dikarenakan semakin tinggi penghasilan, seseorang akan memiliki tuntutan dan harapan yang lebih tinggi pada pelayanan kesehatan yang dibutuhkannya karena mampu secara finansial. Hasil ini juga sejalan pada penelitian (Vuong et al, 2017), seseorang dengan pemasukan atau penghasilan tinggi akan memiliki kebutuhannya dengan lebih baik dibandingkan pada seseorang dengan penghasilan rendah karena seseorang dengan penghasilan tinggi akan rela untuk membayar lebih untuk kebutuhannya dalam hal kesehatan dan mendapatkan pelayanan yg lebih baik (Napirah, 2016). Tingkat penghasilan yang rendah akan berkaitan erat dengan ketidakmampuannya dalam biaya 
transportasi ke pelayanan kesehatan atau biaya kebutuhan lain seperti kebutuhan sehari-hari sehingga tidak merasa butuh pelayanan kesehatan (Gaol, 2013), yang dalam konteks ini adalah layanan fisioterapi antenatal. Maka, pernyataan ini sejalan dengan Teori Maslow yang mengatakan bahwa manusia akan terlebih dahulu memenuhi kebutuhan yang paling dasar untuk mencapai kebutuhan yang lebih tinggi (Bimo, 2010). Satu hal yang perlu diingat oleh semua pihak ialah bahwa di dalam kesehatan terdapat istilah equity yang artinya setiap masyarakat berhak mendapatkan layanan kesehatan yang dibutuhkannya, tidak memandang atau bergantung dari status sosial ekonomi (Gaol, 2013). Teori ini adalah suatu landasan yang kuat untuk selalu mengusahakan pemerataan sosialisasi informasi serta pelayanan kesehatan yang merata bagi setiap orang, karena pada dasarnya kesehatan adalah kebutuhan utama setiap individu dan sudah sewajibnya mendapatkan pemenuha.

\section{KESIMPULAN DAN REKOMENDASI}

Berdasarkan penelitian ini, diketahui bahwa terdapat hubungan yang signifikan antara faktor tingkat pendidikan, tingkat penghasilan keluarga serta tingkat pengetahuan terhadap pembentukan persepsi kebutuhan fisioterapi pada ibu hamil. Lewat penelitian ini diketahui bahwa tidak terdapat hubungan yang signifikan antara persepsi kebutuhan layanan fisioterapi antenatal dengan faktor pekerjaan. Peningkatan efektivitas dalam sosialisasi mengenai layanan fisioterapi perlu dilakukan tidak hanya untuk menjangkau keluarga dengan tingkat pendidikan dan penghasilan tinggi, namun menjangkau seluruh lapisan keluarga guna memperbaiki dan meningkatkan kualitas kesehatan ibu hamil dan janin.

\section{UCAPAN TERIMAKASIH}

Penulis mengucapkan terima kasih kepada anggota Politkenik Kesehatan Kementerian Kesehatan Jakarta 3 dan seluruh pihak yang terlibat secara langsung maupun tidak langsung dalam pengumpulan data, proses analisis data, dan segala bantuan dalam menyusun penelitian ini.

\section{DAFTAR PUSTAKA}

Åhs, A., Burell, G. and Westerling R. 2012. Care or Not Care - that is the Question: Predictors of Healthcare Utilisation in Relation to Employment Status. Int $\mathbf{J}$ Behav Med.;19(1):29-38.

Beckmann C, Ling FW, Barzansky BM, Herbert WNP, Laube DW, Smith RP. 2010. Obstetrics and Gynecology. 6th ed. Philadelphia: Library of Congress Cataloging.

Bimo W. 2010. Pengangtar Psikologi Umum. Yogyakarta, Indonesia: Penerbit Andi.

Field KS, Briggs DJ. Socio-economic and locational determinants of accessibility and utilization of primary health-care. Heal Soc Care Community. 2001;9(5):294-308.

Gaol TL. Pengaruh Faktor Sosiodemografi, Sosioekonomi dan Kebutuhan terhadap Perilaku Masyarakat dalam Pencarian Pengobatan di Kecamatan Medan Kota Tahun 2013. Universitas Sumatera Utara; 2013.

Haposanita R, Jati, Sutopo P, Suparwati A. 2014. Hubungan Antara Persepsi Ibu Hamil Tentang Mutu Pelayanan Antenatal Dengan. J Kesehat Masy. 2(2):157-62.

Howell ER. 2012. Pregnancy-Related Symphysis Pubis Dysfunction Management And Postpartum Rehabilitation: Two Case Reports. J Can Chiropr Assoc.56(2):102-11.

Jacobalis. 2000. Kumpulan Tulisan Terpilih Tentang Rumah Sakit di Indonesia dalam Dinamika Sejarah, Transformasi, Globalisasi dan Krisis Nasional. Jakarta, Indonesia: Yayasan Penerbit IDI.

Jalaludin R. 2007. Persepsi Dalam Proses Belajar Mengajar. Jakarta: Rajawali Press.

Juwita R, Irfan M. 2004. Hubungan Persepsi Mahasiswa Akademi Fisioterapi UKI tentang Profesi Fisioterapi dengan Motivasi Belajar tahun. J Fisioter Indonusa. 2006;6(2):95-112.

Kanakaris,N.K., C. S.Roberts PVG. 2011. Pregnancy related pelvic girdle pain and low back pain in an Iranian population. BMC Med. 9(15).

Liddle, S. and Pennick V. 2015. Interventions for Preventing and Treating Low-Back and Pelvic Pain during Pregnancy. Cochrane Libr. 2015;30(9):1-118.

Listiani I. 2017. Hubungan Tingkat Pendidikan dan Penghasilan Pasien dengan Persepsi Pasien Tentang Mutu Pelayanan Kesehatan di Puskesmas Baki Kabupaten Sukoharjo.

Littik S. 2008. Hubungan Antara Kepemilikan Asuransi Kesehatan dan Akses Pelayanan Kesehatan di Provinsi Nusa Tenggara Timur. Mkm. 2008;3(1):52-61.

Manurung, S. and Nasution S. 2011. Pengetahuan Ibu Primigravida Tentang Adaptasi Fisiologis Selama Kehamilan. J Keperawatan Matern. ;1-5. 
Napirah MR et al. 2016. Faktor-Faktor Yang Berhubungan Dengan Pemanfaatan Pelayanan Kesehatan Di Wilayah Kerja Puskesmas Tambarana Kecamatan Poso Pesisir Utara Kabupaten Poso. J Pengemb Kota;4(1):29-36.

Nayak R, Paes L, K V, Narayan A, Thunga S, P P. 2015. Knowledge , Perception , and Attitude of Pregnant Women Towards the Role of Physical Therapy in Antenatal Care - A Cross Sectional Study. J Heal Allied Sci. 14(4):1-5.

O.Ayanniyi, A. O.Sanya, S. O.Ogunlade. 2017. Prevalence and pattern of back pain among pregnant women attending ante -natal clinics in selected health care facilities. African $\mathrm{J}$ Biomed Res. 2009;9(3):145-56. Kilmartin L. Physical Therapy Management of Thoracic Pain, Lumbar Pain, and Vasovagal Response During Pregnancy. J Women's Heal Phys Ther;41(1):28-41.

Ramachandra P, Maiya AG, Kumar P, Kamath A. 2014. Prevalence of musculoskeletal dysfunctions among Indian pregnant women. J Pregnancy. 2015:1-4.

Richards E, Van Kessel G, Virgara R, Harris P. 2012. Does antenatal physical therapy for pregnant women with low back pain or pelvic pain improve functional outcomes? A systematic review. Acta Obstet Gynecol Scand. 91(9):1038-45.

Sinclair M et al. 2014. How Do Women Manage Pregnancy-Related Low Back And / Or Pelvic Pain? Evidence Based Midwifery.

Suharman M. 2005. Psikologi Kognitif. Suarabaya: Srikandi;

Trisnaniyanti I, Prabandaru Y, Citraningsih. 2010. Perspsi dan Aktivitas Kader PSN DBD Terhadap Pencegahan dan Pemberantasan Demam Berdarah Dengue. Ber Kedokt Masy. 2010;132-7.

Vuong Q et al. 2017. Psychological and SocioEconomic Factors Affecting Social Sustainability through Impacts on Perceived Health Care Quality and Public Health: The Case of Vietnam. J Sustain.;9(1456):1-15.

Wardana BK. 2016. Hubungan Pendidikan dan Pengetahuan Peserta BPJS di Kelurahan Rowosari dengan Pemanfaatan Pelayanan Kesehatan di Puskesmas Rowosari;6(1):4653.

Wibowo, D. A. and Zen DN. 2017. Hubungan Tingkat Pengetahuan dengan Sikap Keluarga Tentang Perawatan Arthritis Rheumatoid pada Lansia di Desa Pamalayan Kecamatan Cijeunjing Kabupaten Ciamis. J Kesehat Bakti Tunas Husada; 17(2):338-56.

Yasobant S et al. 2014. Musculoskeletal Problems Among Pregnant Women: A Facility Based Survey In Odisha. Internati onal J Med Res Heal Sci India;3(2):358.

Yesil P, Oztunc G, Eskimez Z. 2015. An Investigation of Patients 'Perceptions of Nursing Care: Case of Intensive Care. Int $\mathbf{J}$ Caring Sci. ;8(2):412-9. 30.

Yustiani, Langgeng; Abd, Hakim; Paudi; Ritman I. 2013. Hubungan Tingkat Pendidikan Ibu Rumah Tangga dengan Persepsi Penggunaan Kontrasepsi di Kelurahan Tondo Kecamatan Mantikulore Kota Palu. J Elektron Prodi Biol. 2(1):30-5. 